\title{
A TEORIA ÀS AVESSAS E SEUS REFLEXOS NO DIREITO EMPRESARIAL E NO DIREITO DE FAMÍLIA
}

\section{THE THEORY IN REVERSE AND HIS REFLEXES IN THE BUSINESS LAW AND FAMILY LAW}

\author{
Gislaine Fernandes de Oliveira Mascarenhas Aureliano" \\ Carla Bonomo"
}

\begin{abstract}
Resumo: O Estado Contemporâneo nas relações empresariais, assim como em qualquer espécie de relação jurídica, deve ser entendido no sentido de efetivação dos direitos. A teoria às avessas da desconsideração da personalidade jurídica cria no mundo jurídico um avanço, uma expectativa de concretizar questões até então esquecidas ou dormentes, sendo atualmente deferidas pelos magistrados quando se denota a simulação, fraude e/ou abuso de direito por parte do sócio. Os princípios são aplicados, mesmo que de forma implícita, aos casos concretos e geram opiniões satisfatórias para as relações empresariais, levando-se em conta ainda o aspecto da interpretação e argumentação de regras pré-existentes. Apura-se o real sentido da Teoria às Avessas, as suas perspectivas no direito comercial e no direito de família.
\end{abstract}

Palavras-chave: Direito negocial. Relações empresariais. Teoria às Avessas. Efetividade dos Direitos. Direito Comercial e Direito de Família.

Abstract: The contemporary State in Business, as well as in any kind of legal relationship, must be understood in the sense to enforce rights. The called "Theory in Reverse" of disregard of legal entity creates a legal breakthrough, an expectation of achieving issues hitherto forgotten or dormant, and it is currently deferred by the magistrate when there's simulation, fraud and/or abuse of rights by the partner. The principles are applied, even implicitly, in specific instances and they generate satisfactory opinions for business relationships, considering also the aspect of interpretation and discussion of preexisting rules. It investigates the real meaning of the "Theory in Reverse", its prospects in Commercial

Mestre em Direito Negocial na Universidade Estadual de Londrina - UEL. Pósgraduada pela Escola da Magistratura do Estado do Paraná - Jacarezinho. Bacharel em Direito pela Faculdade Estadual de Direito do Norte Pioneiro - Jacarezinho. Docente em Direito Empresarial, Direito Processual Penal, Coordenadora de TCC e Membro Editorial da Revista Impressa e Eletrônica na Faculdade de Educação, Administração e Tecnologia de Ibaiti - FEATI. Docente em Direito Penal e Direito Processual Penal na FANORPI. Oficial de Justiça do Egrégio Tribunal de Justiça do Estado do Paraná Comarca Ribeirão do Pinhal. Email: gi_fernandess@yahoo.com.br

Mestrado em Direito pela Pontifícia Universidade Católica de São Paulo (1993) e Doutora em Direito pela Pontifícia Universidade Católica de São Paulo (2004). Atualmente é professora titular da Universidade Estadual de Londrina, na disciplina Direito Comercial II (Recuperações e Falência). Email: carlabonomo@yahoo.com.br 
Law and Family Law.

Key-words: Law negotiation. Business relationships. Theory in Reverse. Effectiveness of rights. Commercial Law and Family Law.

\section{INTRODUÇÃO}

O Direito Empresarial tem sofrido várias alterações no que pertine aos seus efeitos, objetivos e finalidades. Os homens são reveladores de opiniões diversas e argumentos ímpares, reagindo, muitas vezes, de forma a burlar a própria lei, aproveitando-se de situações benéficas, como a aplicação do princípio da autonomia patrimonial, tão em voga, mas que não merecedora de crédito quando o conjunto comprobatório ficar demonstrada a fraude, simulação e/ou abuso de direito por parte do sócio, ocorrendo, neste caso, a desconsideração da personalidade jurídica.

Diante das modificações e avanços alcançados pelo próprio homem através de seu intelecto, levando-se em consideração a globalização e demais questões hodiernamente apresentadas, surgem situações não regradas, ou seja, que não apresentam dispositivos legais para a real aplicação.

É nesse aspecto que nasce a desconsideração da personalidade jurídica de forma inversa, ou também chamada de Teoria às Avessas, demonstrando ao mundo jurídico a pertinência em sua aplicação diante de questões apresentadas pelos jurisdicionados e que é o tema do presente estudo.

O objetivo é demonstrar a seriedade e relevo da Teoria às Avessas no mundo contemporâneo, através de exposições de decisões de magistrados nesse sentido, tanto no direito comercial quanto no direito de família, quando demonstradas a fraude, simulação e/ou abuso de direito por parte do sócio que transfere seus bens particulares à sociedade empresária de que faça parte, a fim de não quitar seus débitos junto a terceiros envolvidos no litígio.

Ultrapassando barreiras, cria-se um ideal de justiça e perseverança de que efetivamente considerando, o aplicador da lei deve esmiuçar o verdadeiro sentido e conteúdo do casolhe apresentado para, assim, contribuindo com o seu entendimento imparcial, desconsiderar a personalidade jurídica do sócio que assim atua.

A base principiológica é fundamental para a concretização dos direitos violados, mesmo que implicitamente considerada, e nesse aspecto, o presente trabalho tem por finalidade expor as discussões doutrinárias, os argumentos utilizados pelos magistrados a fim de se chegar a um fim social equitativo e digno. Então, a proposta é no sentido de transparecer as ideias hodiernamente utilizadas, e a concretização de direitos, aplicando-se regras através de interpretações realizadas pelos magistrados, com o fim precípuo de aniquilar os atos praticados sob o véu do ilícito. 


\section{TEORIA ÀS AVESSAS E CONCEITO}

Aexpressão "teoriaàsavessasouteoriainversadadesconsideraçãodapersonalidade jurídica” é relevante para o direito negocial no Estado Contemporâneo, pois é a busca pela responsabilização da sociedade no tocante às dívidas ou aos atos praticados pelos sócios, sendo utilizada, para isto, a quebra da autonomia patrimonial.

A desconsideração inversa da responsabilidade ocorre no sentido oposto, isto é, os bens da sociedade respondem por atos praticados pelos sócios, casos em que este obtém o absoluto controle dos bens da sociedade.

Um exemplo para a efetiva aplicação da teoria às avessas, seria a situação de terceiros que, tendo em vista o fato do sócio residir em suntuosa casa, com inúmeros carros importados em sua garagem, deduzindo os terceiros pela teoria da aparência, que não terão prejuízo com o sócio, pelas atitudes e bens que comporta. Todavia, após realizado o acordo, é descoberto que os bens utilizados pelo sócio são de propriedade da empresa, pessoa jurídica. O que fazer? O negócio jurídico já foi celebrado; o terceiro é pessoa infimamente pobre perante o sócio, que apresenta vários bens em seu poder, apesar de estar no nome da empresa; hipótese de fraude?

MônicaGusmão,atravésdesuadoutrina DireitoEmpresarial,argumentaquepode ocorrer a desconsideração da personalidade jurídica inversa, a fim de responsabilizar a pessoa jurídica por atos praticados por seus sócios (GUSMÃO, 2005, p. 75).

O doutrinador Carlos Roberto Gonçalves, através de sua obra Direito Civil Brasileiro,expõeoseguintesobreoassunto:"Caracteriza-sea 'desconsideraçãoinversa' quando é afastado o princípio da autonomia patrimonial da pessoa jurídica para responsabilizara sociedade porobrigação do sócio[...]” (GONÇALVES,2009,p. 219).

Fábio Ulho Coelho, em sua doutrina Curso de Direito Comercial, relata que 'A 'desconsideração inversa' consiste em desconsiderar a autonomia da pessoa jurídica para responsabilizá-la por obrigação do sócio, que desviou seus bens para a pessoa jurídica sob seu total controle (COELHO, 1999, p. 45).

A ilustre doutrinadora Giselda M.F.Novaes Hironaka, através de sua doutrina Direito de Empresas, apresenta a sua opinião acerca da desconsideração inversa da personalidade jurídica, senão vejamos:

Mister recordar que a desconsideração pode também dar-se de maneira 'inversa'. $\mathrm{Na}$ desconsideração tradicional responsabiliza-se sócio por dívida formalmente imputada à sociedade, enquanto na modalidade inversa desconsidera-se a pessoa jurídica para responsabilizá-la por obrigação do sócio (HIRONAKA, 2008, p. 163).

Assim como a desconsideração da personalidade jurídica, a teoria às avessas será aplicada sempre que for apurado o uso abusivo, simulado ou fraudulento 
da pessoa jurídica, prejudicando dessa forma, credores ou terceiros; a aplicação da desconsideração inversa, da mesma forma que a teoria da desconsideração da personalidade jurídica, não visa à anulação da personalidade jurídica, mas apenas a declaração da ineficácia para determinado ato.

\subsection{Separação da Personalidade Jurídica da Sociedade e dos Sócios}

Necessário expor que o princípio da separação da personalidade jurídica da sociedade e dos sócios, ou princípio da autonomia da vontade, não será destruído, atingindo apenas o episódio sem atingir a validade do ato constitutivo da sociedade.

Rubens Requião em trabalho pioneiro no Brasil assegura, através de sua doutrina Curso de Direito Comercial, o seguinte:

Ora, diante do abuso de direito e da fraude no uso da personalidade jurídica, o juiz brasileiro tem o direito de indagar, em seu livre convencimento, se há de consagrar a fraude ou o abuso de direito, ou se deva desprezar a personalidade jurídica, para, penetrando em seu âmago, alcançar as pessoas e bens que dentro dela se escondem para fins ilícitos ou abusivos (REQUIÃO, 1969, p.14).

Portanto, o princípio da separação do patrimônio do sócio e da sociedade é relativizado, através da teoria às avessas, quando o sócio utiliza este princípio como anteparo para prática de fraude, abuso e simulação. Dessa forma, todos aqueles que, valendo-se do manto societário, agirem de modo fraudulento ou abusivo ou simulado, responderão pelos créditos insatisfeitos dos credores sociais.

Desse modo, como visto na doutrina e jurisprudência, a proteção da personalidade jurídica está positivada de tal forma a evitar malícia ou desvirtuamento em sua utilização.

\subsection{Teoria às Avessas e Pressupostos}

Para que efetivamente seja desconsiderada inversamente a personalidade jurídica pelos julgadores, deverão estar presentes alguns pressupostos, quais sejam: o desvio de bens - simulação, a fraude ou abuso de direito, utilizando-se o sócio o manto da autonomia patrimonial a fim de transferir ou esconder bens, prejudicando assim os credores contratantes.

Assim sendo, a pessoa jurídica e os sócios poderão responder por uso abusivo, simulado ou fraudulento da sociedade, tanto diretamente como inversamente, atingindo os bens sociais, no tocante à responsabilização do sócio, ou mesmo do cônjuge empresário, no caso do Direito de Família. Neste aspecto, os bens do sócio estão em nome da sociedade e ficou devidamente comprovada a má-fé por parte do mesmo, sendo desconsiderada a personalidade jurídica de forma inversa a fim de ressarcir o terceiro prejudicado. 
Desconsiderada inversamente a personalidade jurídica, surgem alguns efeitos que merecem ser apresentados: 1) a quebra do princípio da autonomia patrimonial; 2) o alcance dos bens patrimoniais da sociedade; 3) e no Direito de Família, que mormente é utilizada a desconsideração jurídica inversa, a partilha de bens do casal.

No que pertine ao primeiro tópico: a autonomia patrimonial, vale lembrar que os patrimônios e as responsabilidades são diversas e por isso são conservados independentemente da pessoa física e da pessoa jurídica. Neste sentido, foi iniciada uma ampla utilização dessa autonomia patrimonial de forma indevida, surgindo, desse ínterim, a quebra da autonomia patrimonial, desde que verificada a fraude, simulação e/ou abuso de direito, com o fim precípuo de prejudicar terceiros.

Nesse caso, o princípio da autonomia patrimonial é relativizado, em decorrência de que não se pode considerar sempre e sempre o véu protetor das responsabilidades, sendo desfeita quando verificada a situação de fraude, abuso ou simulação, por parte do sócio que registra bens em nome da sociedade empresária com a finalidade de burlar o pagamento de terceiros e, bem como a própria lei.

A quebra da autonomia patrimonial é, sem sombra de dúvidas, um avanço e uma proteção maior ao instituto da pessoa jurídica e esta proteção está na aplicação da desconsideração inversa.

Nesse sentido, o antigo Tribunal de Alçada do Paraná julgou a seguinte Apelação Cível:

Constatando-se que a pessoa jurídica está a encobrir interesses ilícitos de seu sócio, em prejuízo ao direito creditício de terceiro, é de se aplicar a regra da teoria da desconsideração da personalidade jurídica, a fim de assegurar que o bem do devedor, incorporado ao patrimônio da sociedade com o manifesto intuito de fraudar a lei, continue garantindo a execução através da penhora realizada, até ulteriores termos. 6 6â Câmara. Apelação Cível no 74.819-6. Relator Juiz Bonejos Demchuck. Julgado em 24/04/1995.

Assim sendo, a quebra da autonomia patrimonial estará autorizada ao magistrado sempre que forem comprovadas manobras maliciosas por parte dos sócios, prejudicando terceiros e burlando a própria lei.

Necessário expor que a desconsideração inversa é utilizada tanto no Direito Comercial quanto no Direito de Família, perfeitamente aceita quando há a transferência do patrimônio particular do devedor - sócio - à sociedade, com o interesse de desobrigar-se de responsabilidades perante terceiro e, mesmo, no caso de Direito de Família, na ação de separação ou divórcio, na partilha de bens do casal, e ainda no pagamento de pensão alimentícia - isentando o sócio, muitas vezes, da obrigação, em virtude de inexistirem bens passíveis de penhora, em 
decorrência do que expõe o artigo 732, do Código de Processo Civil, quando estiver diante de fase executiva, porque registrou os seus bens pessoais em nome da sociedade empresária, agindo com fraude, simulação e/ou abuso de direito. Neste caso, os bens desviados para a sociedade empresária serão alcançados, ocorrendo uma responsabilidade coletiva e consequente atribuição e vinculação ao pagamento da pensão, assim como na ação de separação e divórcio, quanto à partilha de bens.

Dessa forma, a utilização da desconsideração inversa vem tornar ineficaz a constituição do ato, apenas episodicamente, para julgar a conduta abusiva ou fraudulenta ou simulada do sócio, estando para os demais atos jurídicos válida e eficaz.

Necessário relatar que a desconsideração poderá ser utillizada tanto na fase de cognição, como na execução, nesta constringindo os bens necessários para a satisfação do débito. Não obstante, ao ser aplicada a mencionada desconsideração deve-se ter a plena conviç̧ão e comprovação do nexo entre o prejuízo e o ato praticado, para assim, não serem reconhecidos os efeitos de tais abusos contra os rendimentos do credor alimentar.

\section{TEORIA ÀS AVESSAS E PRINCIPIOLOGIA}

A principal proposta do tema escolhido é orientar na construção de uma sociedade calcada nos princípios fundamentais garantidos na Constituição Federal de 1988: o princípio da isonomia, dentre tantos outros direitos e princípios constitucionalmente protegidos, e demonstrar a real aplicação da teoria às avessas às relações empresariais e com ela interligadas.

No presente estudo, o sócio age como se proprietário fosse dos bens e, com isso, pratica atos com terceiros de boa-fé, negociando, adquirindo bens, todavia o patrimônio particular está registrado no nome da sociedade empresária e não do sócio, e neste caso, o sócio burla a lei, frauda credores, abusa dos atos praticados, simula transferências. Verificando esta hipótese, os bens da sociedade respondem por atos praticados pelos sócios, ante à fraude transparente ou abuso ou simulação, em consideração à aplicação da teoria às avessas aos casos concretos.

A teoria às avessas está sendo aplicada às relações jurídicas, levando-se em consideração os aspectos principiológicos, de forma implícita, ainda tênue.

Quanto à relevância do Poder Judiciário no tema proposto, importante transparecer a Teoria de DWORKIN, em sua obra The Philosophy of the Law. Oxford University Press, que é base para todo o sistema jurídico. Senão vejamos: [...]o sistema jurídico não é um sistema composto unicamente por 'regras' de condutas, que seriam, na versão de HART, primárias (que concedem direitos ou 
impõem obrigações) e secundárias (que estabelecem como e por quem as regras primárias podem ser formadas, reconhecidas, modificadas ou anuladas), cuja incidência sobre um fato excluiria a incidência de regra em sentido oposto, mas também integrado por 'princípios' e 'políticas'. Princípio é todo o 'standard' que não seja regra, é um 'standard' que deve ser observado, não porque permite realizar ou atender a uma situação econômica, política ou social, julgada desejável, mas porque ele constitui uma exigência de justiça e de eqüidade ou de outra dimensão moral (DWORKIN, 1977 apud AGUIAR JR., 2006, p. 226).

Considerando os aspectos acima mencionados, nota-se que a base principiológica é fundamental em todo o sistema legislativo brasileiro, fazendo com que diversos juristas o identifiquem inclusive como método aplicado aos casos concretos, efetivando os direitos.

\subsection{Conceito de Princípio}

Preliminarmente, por força da natureza dos princípios, pelo seu conteúdo, pela sua vagueza ou mesmo pela formulação de regramentos destituídos de sanção imediata, numa primeira abordagem, era negado o caráter de autênticas normas jurídicas aos princípios, não sendo considerados como comandos do Direito.

Em 1990, através da ideia de Eros Roberto Grau, foi detectado um movimento no sentido do reconhecimento de juridicidade aos princípios, passando a serem admitidos pelo Direito como imperativos.

Quanto à estatuição dos princípios, neles também comparece, embora de modo implícito, no extremo completável em outra ou outras normas jurídicas, assim como também ocorre com inúmeras normas jurídicas incompletas.

Celso Antonio Bandeira de Melo em sua doutrina Elementos de Direito Administrativo, relata que o princípio jurídico é:

[...] mandamento nuclear de um sistema, sendo um verdadeiro alicerce desse sistema, disposição fundamental que se irradia sobre diferentes normas compondolhes o espírito e servindo de critério para sua exata compreensão e inteligência, exatamente por definir a lógica e a racionalidade do sistema normativo, dando-lhe sentido harmônico" (MELO, 1980, p. 230).

Miguel Reale relata que o conceito de princípio serve às ciências em geral, expondo o seguinte, em sua obra Filosofia do Direito:

'Princípios' são, pois, verdades ou juízos fundamentais, que servem de alicerce ou de garantia de certeza a um conjunto de juízos, ordenados em um sistema de conceitos relativos a dada porção da realidade. Às vezes também se denominam 'princípios' certas proposições que, apesar de não serem evidentes ou resultantes de evidências, são assumidas como fundantes da validez de um sistema particular de conhecimentos, como seus 'pressupostos' necessários (REALE, 1986, p. 60).

Assim, os princípios têm suas propriedades, diferenciando-se por sua natureza 
(qualitativamente) dos demais preceitos jurídicos, estando os princípios como constituintes de expressão primordial de valores fundamentais expressos pelo ordenamento jurídico, informando as demais normas, como se fornecesse a inspiração para o seu conteúdo.

\subsection{Princípio da Isonomia}

Se há questão que tenha, em todos os tempos, desafiado a inteligência humana e dividido os homens, é o princípio da igualdade. Foram os profetas, os apóstolos e os grandes personagens bíblicos, os primeiros que ocuparam com o tratamento dos semelhantes neste mundo e no outro, perante os homens e em face de Deus.

Paulino Jaques, em sua doutrina Da igualdade perante a lei, argumenta que:

[...] Embora todos, grandes e pequenos, pobres e ricos, sábios e ignorantes, santos e pecadores, devam comparecer, da mesma forma, ao Tribunal Supremo, para o julgamento final, irrecorrível e irrevogável, cada um será, no entanto, julgado 'segundo' suas 'obras' e seus 'caminhos', quer dizer, os iguais em ações e meios terão recompensas ou penas iguais, e os desiguais nisso, evidentemente, receberão prêmios ou castigos diferentes. Foi esse, em suma, o entendimento bíblico do dogma das religiões de que 'todos são iguais perante a Deus', do qual a igualdade dos homens diante da lei não passa de legítima expressão no terreno humano (JAQUES, 1957, p. 19-20).

O direito público francês foi o que formalizou em primeiro lugar a ideia jurídica da igualdade, no direito constitucional, estampando-a no artigo $1^{\underline{0}}$, a famosa Declaração dos Direitos do Homem e do Cidadão, em agosto de 1789.

Nascia, assim, no plano jurídico-positivo um poderoso instrumento de contraposição aos privilégios pessoais e contra a hierarquização das classes sociais que vigorava até então. Surgia também o princípio da isonomia, considerada uma fonte inesgotável de ideias para o ideário igualista que, após a segunda metade do século passado, incendiou a história do pensamento político-econômico.

O preceito magno da igualdade é voltado quer para o aplicador da lei quer para o próprio legislador, e, assim considerando, os indivíduos se nivelam tanto na edição da lei, quanto no momento de sua aplicação.

Aplica-se o princípio acima mencionado para alcançar um ideal de justiça, que, segundo São Tomás de Aquino, consiste em dar a outrem o que lhe é devido, segundo uma igualdade. Segundo Aristóteles, a verdadeira igualdade é aquela que pratica a igualdade entre os iguais e a desigualdade entre os desiguais.

O princípio da justiça social, assim, conforme a concepção de existência digna cuja realização é o fim da ordem econômica e compõe um dos fundamentos da República Federativa do Brasil. 
Paulo Bonavides, através de sua doutrina Curso de Direito Constitucional, expõe o seguinte acerca do princípio da isonomia:

O centro medular do Estado social e de todos os direitos de sua ordem jurídica é indubitavelmente o princípio da igualdade. Com efeito, materializa ele a liberdade da herança clássica. Com esta compõe um eixo ao redor do qual gira toda a concepção estrutural do Estado Contemporâneo [...] De todos os direitos fundamentais, a igualdade é aquele que mais tem subido de importância no Direito Constitucional de nossos dias, sendo, como não poderia deixar de ser, o direito-chave, o direito-guardião do Estado social [...] Na judicatura do Tribunal Constitucional da Áustria, por exemplo, ele não apenas predominou quantitativamente como desalojou todos os demais direitos fundamentais (BONAVIDES, 1993, p. 301-2).

Com referência à concretização do princípio da isonomia, pode-se dizer que é dependente do critério de diferenciação e, é nesse patamar que é encaixado o tema desconsideração inversa da personalidade da pessoa jurídica, mesmo porque o princípio da isonomia em sua essência nada diz quanto aos bens ou aos fins de que é servida a igualdade a fim de diferenciar ou igualar as pessoas, e estas são iguais ou desiguais de acordo com um critério diferenciador.

Duas pessoas são formalmente iguais ou desiguais em razão da idade, do sexo ou da capacidade econômica e, é nesse último ponto, que é interposta a relação Teoria às Avessas e Princípio da Isonomia, porque essa diferenciação somente adquire relevo na medida em que é assegurada uma finalidade, de acordo com o critério, e este é relacionado no presente estudo através do aspecto econômico.

Hodiernamente, sócios perfazem acordos absurdos com terceiros, prejudicandoos em vista de não possuírem patrimônio, porque este se encontra registrado no nome da pessoa jurídica. Os terceiros prejudicados estão em situação desfavorável em decorrência da má intenção dos sócios da empresa. A fim de evitar esses enigmas, surge a aplicação do princípio da isonomia no sentido de que os dispositivos legais brasileiros que tratam da desconsideração da personalidade jurídica sejam efetivamente aceitos da forma inversa, retirando o véu da pessoa jurídica, deslocando a autonomia patrimonial daqueles que burlam a lei, não satisfazendo os seus negócios, agindo com fraude e/ou abuso de direito e/ou simulação.

Com esse entendimento, os direitos serão garantidos a todos, em virtude da efetivação de dispositivos legais, aplicados de forma inversa, mas que sustentadores do princípio da isonomia aos casos concretos, evitando abusos e má-fé por parte de sócios que vivem às custas da autonomia patrimonial, registrando os seus bens pessoais em nome da sociedade empresária, com a finalidade de não satisfação do interesse alheio. 


\subsection{Princípio da Dignidade da Pessoa Humana}

O princípio da dignidade da pessoa humana apresenta dois aspectos: o negativo e o positivo. Assim considerando, constitui não apenas a garantia negativa de que a pessoa não será objeto de insultos e afrontas, mas implica também, um sentido positivo, o pleno desenvolvimento da personalidade individual.

O referido princípio impõe limites à atuação estatal, objetivando impedir que o poder público venha a violar a dignidade pessoal, mas também alude que o Estado-Juiz apresente como meta permanente, proteção, promoção e realização concreta de uma vida com dignidade para todos, sustentando a necessidade de uma política da dignidade da pessoa humana e dos direitos fundamentais.

Ainda referente aos princípios, que são a base de todo o sistema operacional do direito, Eros Roberto Grau expõe, acerca do princípio da dignidade da pessoa humana em sua obra A ordem econômica na Constituição de 1988, o pensamento de que, a dignidade da pessoa humana constitui o núcleo essencial dos direitos humanos, muito embora assuma concreção de direito individual. Necessário relatar ainda que a dignidade da pessoa humana fundamenta e confere unidade não apenas aos direitos fundamentais - direitos individuais e direitos sociais e econômicos - mas também à própria organização econômica, não sendo apenas um fundamento da República Federativa do Brasil, plenamente transparente na Constituição Federal de 1988, mas se volta inclusive ao mundo do ser, que é a ordem econômica. Deste pensamento, conclui que a dignidade da pessoa humana é um princípio balizador, isto é, é a base no ordenamento jurídico, em que o equilíbrio das relações jurídicas, sociais, econômicas são contornos à hipótese da não redução do princípio da dignidade da pessoa humana, sob pena de transgressão de todos os direitos fundamentais, visto que é o núcleo do ordenamento atual (GRAU, 2002).

Não restam dúvidas de que todos os órgãos, funções e atividades estatais estão acoplados ao princípio da dignidade da pessoa humana, impondo-lhes um dever de respeito e proteção, expresso tanto na obrigação por parte do Estado de renunciar ingerências na esfera individual contrárias à dignidade pessoal, quanto no dever de protegê-la contra agressões provenientes de terceiros, como é o caso de sócio que registra todo o seu patrimônio particular em nome da pessoa jurídica para burlar a lei e agindo, assim, acreditando estar sob o manto da autonomia patrimonial.

O princípio da dignidade da pessoa humana está intimamente conectado com o tema da desconsideração da personalidade jurídica de forma inversa, porque não apenas impõe um dever de abstenção, de respeito, mas também de condutas 
positivas por parte do Estado-Juiz, tendentes a efetivar e proteger a dignidade dos indivíduos que tiveram seus direitos violados em decorrência de atuação de sócio que abusa, simula e/ou comete fraude.

Por essa razão, a tendência do direito contemporâneo é no sentido de não mais limitar-se à enunciação de um postulado formal e abstrato de isonomia jurídica, mas sim de fixar medidas concretas e objetivas, capazes de aproximar as questões sociais, políticas e econômicas entre os jurisdicionados, pois a dinâmica da evolução social chama o Estado a dirimir conflitos entre as forças de capital, do trabalho e da ordem econômica, submetendo os princípios do bem comum e da justiça social às relações interpostas, principalmente quando há a conexão com a ordem econômica, porque moldam um padrão desejável aos processos econômicos de determinada sociedade, atuando com limitações e incentivos para a sua efetiva realização.

Assim, quando o Estado intervém na atividade econômica, por força do princípio constitucional fundamental do Estado Democrático de Direito, deve utilizar os instrumentos e mecanismos postos à sua disposição diretamente pelo Legislador Constitucional e, além disso, ir ao encontro de princípios que o façam assumir e agir sob uma perspectiva positiva, efetiva e presencial, pois as balizas da intervenção serão, sempre e sempre, ditadas pela principiologia constitucional, pela declaração expressa dos fundamentos do Estado Democrático de Direito, dentre eles a dignidade da pessoa humana, os valores sociais do trabalho e da ordem econômica.

Conclui que qualquer interpretação sobre a devida ou indevida intervenção estatal deverá ser analisada diante dos princípios e dos próprios fundamentos do Estado Democrático de Direito apresentados no sistema; o princípio da dignidade da pessoa humana impõe limites à atuação estatal, porque obstrui o Poder Público a violar a dignidade pessoal, mas também implica ao EstadoJuiz atuar com meta permanente, protegendo a vida com dignidade a todos, sustentando a necessidade de uma política da dignidade da pessoa humana e dos direitos fundamentais, inclusive à ordem econômica, no sentido de promover uma relação dependente entre aquele - sócio - enganador em face de um terceiro que age de boa-fé numa negociação envolvendo patrimônio, cuja finalidade precípua é o recebimento do débito.

Então, por força da dimensão intersubjetiva deste princípio, há a necessidade de um dever geral de respeito por parte de todos (e de cada um isoladamente) os integrantes da comunidade de pessoas para com os demais e, para, além disso, e de certa forma, até mesmo um dever das pessoas para consigo mesmas, ressaltando a ideia da ordem econômica, prevalecendo a aplicação dos princípios intimamente 
interligados com os dispositivos legais colocados à disposição do aplicador, fazendo surgir o ideal de Justiça, mesmo inexistindo texto legal explícito acerca do assunto, mas que com algum dispositivo legal faz relação.

Assim considerando, há a perfeita união entre o princípio da dignidade da pessoa humana à teoria às avessas ou teoria da desconsideração inversa da personalidade jurídica, porque o terceiro prejudicado terá seus direitos efetivados, anulando a fraude, o abuso ou a simulação praticados pelo sócio de empresa que corporifica todo o seu patrimônio na pessoa jurídica, agindo de má-fé, a fim de impedir que seus bens sejam constritados judicialmente. Posto isto, é levantado o véu da pessoa jurídica, de forma a garantir a efetividade dos direitos, fundamentando tal decisão com fulcro em dispositivos legais, mas de forma invertida, porque no atual sistema jurídico, ainda não foi apresentado texto legal específico sobre o assunto, isto é, de acordo com o artigo 50, do Código Civil, há a desconsideração da personalidade jurídica quando a sociedade empresária burla a lei, repassando seus bens em nome do sócio; o que ocorre no presente caso e é o estudo deste trabalho, a ocorrência de sócio que utiliza da má-fé e repassa seus bens pessoais em nome da sociedade empresária, com o fim precípuo de não satisfação de seu débito particular perante terceiros contratantes ou que tenha alguma relação de ordem econômica.

\subsection{Princípio da Razoabilidade}

O princípio da razoabilidade é um parâmetro de valoração dos atos do Poder Público, principalmente, do Poder Judiciário, aferindo se eles estão sendo informados pelo valor superior inerente a todo o ordenamento jurídico: a justiça.

Sendo mais fácil de ser sentido do que conceituado, o princípio da razoabilidade propõe o que é razoável, o que seja conforme a razão, supondo equilíbrio, moderação e harmonia, correspondendo ao senso de justiça, comunicando com os valores vigentes de dado lugar e momento. É o não arbítrio, ou seja, para o efetivo aproveitamento, há a necessidade de uma avaliação da correlação entre o que está sendo promovido com os reais efeitos decorrentes da necessidade de sua aplicação.

Com referência à Teoria Inversa, encaixa-se perfeitamente o princípio da razoabilidade, já que, inexistindo norma legal estatuindo a desconsideração inversa da personalidade jurídica e, admitindo que os princípios são superiores às próprias regras, como se pode verificar acima, não há dúvida que é razoável que seja desconsiderada a pessoa jurídica da empresa para satisfazer interesse de terceiro de boa fé que contratou com o sócio da empresa, ou que alguma relação de crédito-débito possua com o mesmo, burlando o sócio a própria lei, 
registrando o seu patrimônio em nome da sociedade empresária, sob o interesse da existência da autonomia patrimonial havida no direito empresarial.

Ocorre que, neste momento e neste caso específico, o levantamento do véu da personalidade jurídica se faz necessário, destruindo a autonomia patrimonial para a satisfação de terceiros incluídos na relação jurídica entre o sócio, considerando os bens que guarnecem todo o aparato da sociedade, comprovando, em todos os casos, que houve a fraude, abuso de direito, simulação por parte do sócio.

Os fundamentos primordiais ao deferimento da desconsideração inversa da personalidade jurídica são revelados diante do disposto no artigo 50, do Código Civil Brasileiro, embora possuam outros regramentos em leis esparsas, de forma inversa, ou seja, retirando o manto protetor da sociedade empresária que é a autonomia patrimonial, com a finalidade precípua de garantir a efetividade de direitos de terceiros envolvidos numa relação pertencente ao direito empresarial e também a outros direitos, como o direito de família, que será analisado posteriormente, desconsiderando os bens da sociedade empresária ao pagamento de dívidas do sócio, em virtude deste ter praticado atos de forma fraudulenta, abusiva ou simulada, repercutindo, assim, positivamente o elo de ligação entre os referidos princípios, mesmo que de forma implícita, e os dispositivos legais.

\subsection{A Possibilidade de Aplicação Imediata dos Princípios a Casos Concretos}

Considerando que os princípios são dotados de um elevado grau de abstração, dotados de vagueza, de abertura, o que não significa impossibilidade de determinação, podem ser integrados por meio de interpretação e aplicação, sobremodo através de outras normas e até mesmo em relação a situações específicas, como decisões judiciais no que se refere à aplicação da Teoria Inversa da Desconsideração da Personalidade Jurídica aos casos concretos, como se poderá verificar adiante, ao passo que as demais normas (regras) possuem um menor grau de abstração e mais alta densidade normativa.

Pelo fato de os princípios serem dotados de vagueza, hospedando as grandes linhas, orientando todo o ordenamento jurídico, não significa dizer que os princípios são inteiramente ou sempre genéricos e imprecisos, aliás, possuem um significado determinado, com alto grau de concretização, avaliados diante da situação real apresentada.

Isso é relacionado perfeitamente à desconsideração inversa da personalidade jurídica, sob o entendimento de que os princípios norteadores não podem deixar de ser aplicados, em virtude da ausência de regramento específico sobre o assunto, não devendo o magistrado abandonar o instituto da desconsideração da personalidade jurídica caso ocorra a fraude, o abuso de direito, a simulação 
por parte do sócio, atingindo credores, pessoas inocentes e terceiros envolvidos. Deve atingir o patrimônio da pessoa jurídica, quando existente um conjunto comprobatório merecedor. Existem inúmeros julgados acerca do assunto, que serão relacionados em frente.

Assevera Eros Grau, em sua obra $A$ ordem econômica na Constituição de 1988 (interpretação e crítica), que:

[...] a determinação de sentido dos princípios depende sempre do contexto, correspondendo ao significado que os respectivos valores assumem na realidade histórica: o ordenamento jurídico não constitui um conjunto de regras jurídicas cujo sentido e alcance independe do contexto político e social, mas sim que tais regras estão subordinadas a fins em função dos quais devem ser interpretadas (GRAU, 1990, p. 94).

Portanto, da generalidade e da vagueza dos princípios, decorre a plasticidade que os mesmos apresentam, permitindo-lhes amoldarem às diferentes situações e assim acompanharem o passo da evolução social. É uma característica predominantemente formal, pois se prende também antes à expressão linguística dos princípios, devendo ser conciso em dado contexto, refletindo com exatidão a tradução dos valores mais onorosos e oportunos diante do caso apresentado.

Walter Claudius Rothenburg relata em sua doutrina Princípios Constitucionais que:

Desconsiderar que os princípios já carregam um certo e suficiente significado, e sustentar sua insuperável indeterminação, representa desprestigiar sua funcionalidade em termos de vinculação (obrigatoriedade), continuandose a emprestar-lhes uma feição meramente diretiva, de sugestão, o que não se compadece, absolutamente, com a franca natureza normativa que se lhes deve reconhecer (ROTHENBURG, 1999, p. 22).

Os princípios são capazes de recepcionar as mudanças ocorridas no seio da sociedade, sem que isto importe uma contínua modificação do texto de lei, sendo lembrado, nesse patamar, o aspecto da desconsideração da personalidade jurídica de forma inversa, já que não se poderia deixar de aplicar o princípio da igualdade, assim como o princípio da razoabilidade e o princípio da dignidade da pessoa humana às pessoas envolvidas num processo em que o sócio de uma empresa age com fraude, simulação, abuso de direito, registrando seus bens pessoais em nome da sociedade empresária, com o fim de satisfazer obrigação por ele realizada em prejuízo das demais pessoas envolvidas. Neste caso, não poderia o sócio ser acobertado pela autonomia patrimonial.

Assim considerando, a vagueza não é um defeito que os princípios apresentam, 
senão que uma espécie sua de ser, justamente para suprir a ausência de norma regulamentadora a casos em que as mudanças sociais ocorrem e devem ser solucionadas, como se pode verificar na desconsideração inversa da personalidade jurídica.

A enunciação dos princípios de um sistema tem, portanto, uma primeira utilidade evidente: ajudar no ato de conhecimento, porque a identificação dos princípios é o meio mais eficaz para distingui-lo de outro sistema global.

\section{TEORIA ÀS AVESSAS NO ESTADO CONTEMPORÂNEO - GLOBALIZAÇÃO}

Hodiernamente, o progresso da ciência e das técnicas são os novos aceleradores contemporâneos, necessitando de uma reflexão independente sobre o tempo, um pensamento sobre como explicar os problemas mundiais, cujas condições e situações precisam ser modificadas, e para que isto ocorra, há a necessidade de utilização de métodos mais simples.

A ideia central repousa em analisar os princípios fundamentais, aparecendo a persistência sobre o papel da ideologia derivada de instrumentos que, ao mesmo tempo, dá para se fazer o mal, como, aliás, também se faz o bem, surgindo desse aspecto, o papel do intelectual, do pensamento livre, do jurista, do magistrado.

O processo de produção da globalização revelada como uma ameaça entre a economia contemporânea - finanças - território, em que a emergência de novas variáveis centrais e o papel dos pobres na produção do presente e do futuro, convencendo de que a história universal apenas está começando e, é em virtude disso, que surge a aplicação da teoria às avessas neste mundo globalizado, como uma possibilidade in abertus ao futuro de uma nova civilização planetária.

São vários os protagonistas na produção da globalização, dentre eles o dinheiro, numa polarização - riqueza e pobreza -; o extermínio da natureza; a segmentação dos mercados; a população envolvida nesse processo ameaçador. E, neste aspecto, nasce a Teoria às Avessas com a ideia de efetivação dos direitos de terceiros envolvidos numa globalização infinita, cujas relações são de mercado, patrimônio e familiares, ressaltando a questão do Direito de Família, neste último, levantando o véu da sociedade empresária quando o sócio age de forma fraudulenta, abusiva e/ou simulada, repassando seu patrimônio particular no nome da sociedade empresária com a finalidade precípua de não liquidar suas dívidas perante os seus credores.

A tendência é ser substituída a alienação por uma nova consciência - uma nova filosofia moral - que não será a dos valores mercantis, mas sim a da solidariedade e da cidadania, a da aplicação de princípios como o da isonomia, da dignidade da pessoa humana e da razoabilidade, sendo coerente a efetividade de direitos de terceiros envolvidos num processo ameaçador e opressor. 


\subsection{Convívio em Sociedade como Decorrência das Necessidades do Homem - Aplicação da Teoria às Avessas}

Levando em consideração a exposição anteriormente referida, presente está a dificuldade do homem, como um ser hermenêutico que é, viver em sociedade, já que as dificuldades de relacionamento entre os empresários se sobressaem, quando é deixado de lado a ideia de justiça.

Os perdedores - maioria - estão em desgaste com a própria identidade, porque não percebem as fatalidades ocasionadas no mundo globalizado em que a economia é o cerne, alicerce e, que muitas vezes, vêem ameaçados perante a própria lei, ou por falta dela.

Tecidos estes comentários, é ofertado, neste momento, um espírito crítico de atenção e percepção do homem, em razão de sua própria natureza, o qual precisa viver em sociedade e, para isso, necessita de regramentos que o faça crescer como ser humano justo e fraterno, que obtenha do legislador e do próprio magistrado a efetividade de seus direitos, banalizados diante de tantos privilégios ofertados em prol do devedor e, então burlador da lei, muitas vezes assim considerado.

Sábias as palavras de Aristóteles quando relata que o homem é por natureza um animal social, remetido à reflexão mediante a qual se pode colocar em foco os atributos, as necessidades e as possibilidades do homem (apud, GOMES, 2008).

O ser humano deve ser o caçador de si mesmo, no sentido de buscar, perguntar, argumentar sobre os fatos e interesses apresentados pelas demais pessoas. A finitude e o desejo de auto-superação devem lançar no ser humano uma contínua procura, buscando perspectivas, a fim de satisfazer as condições econômicas e mesmo potenciais, investindo o seu conhecimento nas leis e princípios que o asseguram, num relacionamento sadio, em que haja uma isonomia entre todos.

Em tempos de globalização econômica, prevalecendo a preocupação com o dinheiro, em comprar, negociar, é sustentada a necessidade de continuidade da vida humana no planeta e, que esta seja vivida de modo correspondente à dignidade inerente a todo ser humano.

Para o psicanalista, teólogo e pedagogo Rollo May em sua doutrina A coragem de criar, relata que "a coragem é necessária para que o homem possa ser e vir a ser. Para que o eu seja é preciso afirmá-lo e comprometer-se. Essa é a diferença entre os seres humanos e o resto da natureza" (MAY, 1982, p. 10).

Assim considerando, o homem deve evoluir na medida em que o mundo evolui, e nesse sentido, as leis também devem se adequar aos casos concretos, para que não exista a impossibilidade de aplicação do ideal de justiça que há tempo vem sendo esquecido. Nesse aspecto, entende-se que, apesar de inexistir texto legal 
acerca da desconsideração inversa da personalidade jurídica, muitos magistrados já a aplicam a fim de salvaguardar interesse de terceiros de boa-fé que contratam com sócio de má-fé, ou que com ele tenha uma relação de dependência - crédito - débito.

A tão sonhada autonomia patrimonial, questionada e estimada, acaba sendo derrubada em consideração à abrangência do aspecto econômico, motivo pelo qual, muitos magistrados reconhecem a inquietude de credores, que se espraiam em problemas que a própria lei deixa a desejar.

A Teoria às Avessas é o ideal de justiça, utilizada para sanar as dificuldades hodiernamente apresentadas no mundo jurídico.

\section{RELEVÂNCIA DA TEORIA ÀS AVESSAS NO ESTADO CONTEMPORÂNEO E SUA ABRANGÊNCIA NO MUNDO REAL - JURISPRUDÊNCIAS}

O assunto é relevante para o Estado Contemporâneo nas relações empresariais, interligando o Direito Empresarial e o Direito de Família, pois não basta o Estado utilizar os meios e instrumentos constitucionalmente postos à sua disposição, apenas nos estritos limites da legalidade, devendo a implementação das técnicas de intervenção estatal no domínio econômico se dar de forma a atender o interesse público concretamente apresentado, portanto, legitimamente, e de forma razoável, em que os meios e as técnicas a serem utilizadas pelo Poder Público sejam realmente idôneos aos fins pretendidos pela Constituição Federal e pelas Leis, pois só assim será dado real e efetivo cumprimento a este trabalho.

Especificamente acerca da teoria às avessas ou da desconsideração da personalidade jurídica inversa, convém apresentar algumas jurisprudências e, inclusive o Enunciado n. 283 da IV Jornada de Direito Civil do CJF (Conselho da Justiça Federal), autorizando a desconsideração da personalidade jurídica inversa, devendo o magistrado fundamentar a sua decisão em todas as situações lhe apresentadas:

TJSC. Desconsideração da personalidade jurídica denominada 'inversa'. Art. 50 do CC/2002 e Enunciado n. 283 da IV Jornada de Direito Civil do CJF. O interlocutório que desconsidera inversamente a personalidade jurídica de sociedade comercial, fazendo com que a empresa responda com seu patrimônio pela dívida pessoal do sócio, está circunscrito aos pressupostos do art. 50 do atual Código Civil, cabendo ao juiz, fundamentadamente, apontar as razões do seu convencimento, seja pelo acolhimento ou rejeição do pedido, sob pena de vulneração aos arts. 93, IX, da CRFB, e 165, do CPC, dispositivos que transmitem a necessidade de motivação nas decisões judiciais, ainda que concisa, sob pena de nulidade.

É cabível a desconsideração da personalidade jurídica denominada 'inversa' para 
alcançar bens de sócio que se valeu da pessoa jurídica para ocultar ou desviar bens pessoais, com prejuízo a terceiros (SANTA CATARINA, 2006, p. 30).

Portanto, conforme argumentos acima expostos, para o deferimento por parte do magistrado à desconsideração inversa da personalidade jurídica, devem estar preenchidos os pressupostos que já foram analisados em item anterior. Caso contrário, não há motivo para a desconsideração inversa e, aliás, devem ser as decisões sempre fundamentadas.

De forma intimamente implícita, subentende-se que os princípios basilares de todo o ordenamento jurídico estão sendo averiguados no ato da decisão, justamente porque são o cerne de todo o liame jurídico. Não há necessidade de o magistrado justificar a utilização dos mesmos, se decorrentes de normas préexistentes e utilizadas de forma inversa.

A demonstração é de que os princípios, uma vez utilizados, seja de forma explícita ou de forma implícita, servem de embasamento na aferição de normas transcritas no ordenamento jurídico.

Não raro, a desconsideração da personalidade jurídica de forma inversa tem sido aceita e deferida pelos magistrados não somente quando se verifica a situação de relação entre sócio e terceiro envolvido especificamente numa relação de negócios, mas também em relações direcionadas no Direito de Família.

Assim, a decorrência da aplicação e aceitação de dispositivos legais são primordiais, mas o embasamento muitas vezes se dá de forma inversa, justamente para acomodar as reais situações apresentadas, em virtude de não regramento atualmente existente. E é nesse ínterim que surgem as explicações para a adequação das regras do ordenamento jurídico ao mundo social, globalizado, e a principiologia aplicada, mesmo de forma tímida e implícita, às situações colocadas no âmbito jurídico.

Vale ressaltar os julgados do Egrégio Tribunal de Justiça do Estado do Rio Grande do Sul no tocante à adequação da desconsideração em matéria de separação judicial, partilha, alimentos, dentre outros, estão os seguintes:

APELAÇÃO. PRESTAÇÃOJURISDICIONAL INSUFICIENTE. INOCORRÊNCIA. MARCOINICIALDAUNIAOESTÁVEL. ESPECIFICAÇÃO.VALORIZAÇÃODE COTAS SOCIAIS. PARTILHA. DESCONSIDERAÇÃO DA PERSONALIDADE JURÍDICA. CABIMENTO. [...] As cotas sociais das empresas eram de patrimônio exclusivo do de 'cujus'. No entanto, a valorização experimentada por tais cotas durante o período em que o de 'cujus' viveu em união estável é patrimônio comum que, por isso, deve ser partilhado. Ficou demonstrado que o de 'cujus' abusou da personalidade jurídica de suas empresas, ao utilizar de forma indevida delas para o fim de ocultar bens passíveis de partilha. Nesse contexto, cabível desconsiderar 
a personalidade jurídica das empresas. REJEITARAM A PRELIMINAR E NEGARAM PROVIMENTO AO PRIMEIRO APELO. UNANIME. DERAM PARCIAL PROVIMENTO AO SEGUNDO (RIO GRANDE DO SUL, 2006).

Descabe escudar-se o devedor na personalidade jurídica da sociedade comercial, em que está investido todo o seu patrimônio, para esquivar-se do pagamento da dívida alimentar. Impõe-se a adoção da 'disregard doctrine', admitindo-se a constrição de bens titulados em nome de pessoa jurídica para satisfazer débito (RIO GRANDE DO SUL, 1998).

Assim considerando, fica evidenciada a fraude e o abuso de direito e a simulação por parte do sócio, quando este faz uso da pessoa jurídica com a finalidade de ocultar bens passíveis à partilha, ou quando este se furta da sociedade para defender seu patrimônio pessoal por força de dívidas contraídas junto a terceiros ou, mesmo oculta seus bens ao pagamento de pensão alimentícia e, nesse sentido, há a necessidade neste e em qualquer situação ou caso, a utilização da cautela, devendo o magistrado, sobretudo, verificar a presença dos pressupostos tratados e analisados em item anterior, quais sejam: a fraude, o abuso do direito e/ou a simulação, utilizados com a finalidade de prejudicar terceiros.

Também é perfeitamente aplicável a desconsideração inversa e o efetivo alcance dos bens transferidos à sociedade quando se busca a majoração da pensão alimentícia baseada no aumento da fortuna do alimentante e na necessidade do alimentado. Nesse caso, o devedor de alimentos dissimula a sua condição de sócio majoritário da pessoa jurídica e transfere grande parte do capital social para interposta pessoa, para numa revisão de alimentos afirmar que não é sócio majoritário, mas apenas um mero prestador de serviços à sociedade, buscando ao final, o não aumento da pensão alimentícia.

A conclusão a que se chega é que a desconsideração inversa da personalidade jurídica será aplicada pelos magistrados sempre que houver transferência de bens matrimoniais para uma pessoa jurídica visando ao prejuízo da meação ou da partilha de bens, como ao prejuízo ao recebimento da prestação alimentícia, e, ainda, sendo inclusive, utilizada quando o sócio detém absoluto controle da sociedade.

Seguindo a mesma linha de raciocínio, quando o sócio, que também é cônjuge, preocupado com a partilha judicial, retira da sociedade empresarial às vésperas da ação de separação ou divórcio, transferindo a sua participação para outro sócio, burlando a lei, inclusive pela questão de partilha de bens e, após a separação judicial, o sócio fraudulento retorna à empresa e à livre administração dos bens que eram comuns ao casal, com todos os bens que anteriormente já lhe pertenciam, é verificada, em ambos os casos, a presença de fraude, simulação 
e abuso do direito por parte do sócio em prejuízo de terceiro envolvido, assim considerando, há a necessidade da desconsideração inversa da personalidade jurídica, retirando o véu da autonomia patrimonial e aplicando, mesmo que de forma implícita, a regra de que todos são iguais perante a lei, há a presença da dignidade da pessoa humana e, ainda, pelo princípio da razoabilidade, é razoável e necessária a aplicação da Teoria às Avessas. Diante dessas práticas ilícitas, o magistrado desconsidera a personalidade jurídica de forma inversa, no âmbito da sentença judicial, lançada no processo de separação, divórcio ou de dissolução de união estável, as alterações contratuais que transferiram ou reduziram a participação social do cônjuge empresário, voltando assim, ao estado anterior da flagrante apropriação da meação do cônjuge despojado ou, mesmo na situação de prestação alimentícia, segue o mesmo entendimento.

Nesse sentido, vale apresentar a seguinte jurisprudência:

PARTILHA - Separação controvertida em divórcio - Regime da comunhão universal de bens - Meação - Compromissário que, já casado, cede direitos sem a anuência da mulher - Desconsideração - Sentença de partilha homologada respeitando a meação - Sentença mantida - Recurso improvido (SÃO PAULO, 1998).

O Tribunal de Justiça do Rio Grande do Sul ao julgar Agravo de Instrumento entendeu que:

EMBARGOS DE TERCEIROS. 'Disregard' ou desconsideração da personalidade jurídica. Sociedade por quotas formada por concubinos. Arrolamento de bens. Deve ser desconsiderada a personalidade jurídica de sociedade por quotas formada por dois sócios, concubinos casados pelo religioso, rejeitando-se pedido de liminar em embargos de terceiro promovidos pela sociedade, visando obstar arrolamento de bens promovidos pela mulher. Possibilidade de fraude pelo varão, ocultado sob o manto da pessoa jurídica, este, em realidade, age em nome próprio e não da sociedade. Agravo improvido. Unânime (RIO GRANDE DO SUL, 1993).

Assim sendo, o deferimento da desconsideração inversa da personalidade jurídica pelo magistrado, faz com que ocorra o retorno ao monte conjugal dos bens desviados fraudulentamente para a pessoa jurídica, a fim de serem partilhados os bens ao final.

Ficou comprovado que ocorrerá a desconsideração inversa no âmbito do direito familiar, no que tange aos alimentos, conforme já foi relatado, quando o alimentante procura mascarar, aproveitando do manto da pessoa jurídica, escondendo sua real capacidade econômica e financeira da pessoa física, a qual tem o dever legal de alimentos. E, nesse aspecto, o alimentante quando é sócio de 
alguma sociedade empresária, aproveita desse fato para agir omitindo sob o véu empresarial os bens que possui.

Atua também de forma fraudulenta, e é motivo para a desconsideração inversa da personalidade jurídica, o caso do ex-cônjuge que hesita em prestar alimentos declarando que possui baixos rendimentos, não obstante, a sua conduta pública não condiz com a presente postura apresentada nos autos, ostentando luxo e riqueza. Nesse caso, a aplicação da desconsideração inversa da personalidade jurídica e dos princípios embasadores já estudados, mesmo que de forma implícita, são utilizados para o devido caso, a fim de ocorrer a justa solução para o litígio alimentar.

E, se não bastasse, merece ser apresentada a situação de pais ou cônjuges insensíveis que utilizando a pessoa jurídica que integram como sócios para montar diversas estratagemas, com o fim precípuo de impedir que o autor da ação de alimentos possa demonstrar, através de dados concretos, os reais rendimentos por eles percebidos ou os seus respectivos bens particulares, pois transferem seu patrimônio à pessoa jurídica, burlando a lei.

Relativamente ao direito comercial, nas sociedades por quotas, a aplicação da desconsideração inversa se dá com a retirada do véu da autonomia patrimonial. Existem jurisprudências acerca do assunto:

SOCIEDADE POR QUOTAS - Ausência absoluta de patrimônio - existência meramente formal - manifesto prejuízo aos credores - presunção de fraude Aplicação da teoria da desconsideração da pessoa jurídica - Recurso Provido (SÃO PAULO, 1993).

DIREITO PRIVADO NÃO ESPECIFICADO. EXECUÇÃO DE SENTENÇA. Ação de execução de sentença. Preliminar de nulidade da execução rejeitada. Os títulos exeqüendos foram acostados aos autos da execução, conforme se verifica dos documentos que instruem o processo. Além do mais, não há falar em iliquidez quando a apuração do 'quantum debeatur' bastem cálculos aritméticos, o que foi devidamente providenciado pela parte. Mérito. Muito embora na aplicação da 'disregard doctrine', parte-se do pressuposto que responde o sócio com seu patrimônio particular pela obrigação da empresa, o direito não a aplicação da teoria da desconsideração de forma inversa quando o devedor cria uma veste jurídica para tentar defender seu patrimônio particular ameaçado de alienação judicial por força de dívidas contraídas junto a terceiros. Caso em que o princípio da separação patrimonial deve ser superado e ceder em face de circunstancias especiais e excepcionais diante da prova robusta de fraude por parte do sócio para desfrutar dos benefícios de sua posição, restando assente que a separação da pessoa jurídica da pessoa física é mera ficção legal, não sendo justificável que o sócio se 
esconde sob o manto desta sociedade fuja de sua responsabilidade ou de seu fim social, para alcançar benefícios e interesses antisociais. Recurso Improvido por maioria. Preliminar rejeitada (RIO GRANDE DO SUL, 2004).

SOCIEDADE POR QUOTAS - aplicação da desconsideração da personalidade jurídica - transferência da quase totalidade das quotas a esposa mediante alteração contratual - executados que fogem ao confronto com a justiça, deixando de nomear bens a penhora - Recurso não provido (SÃO PAULO, 1989).

No Egrégio Tribunal de Justiça do Estado do Paraná, recentemente, foi julgada uma apelação cível, relativa à desconsideração inversa da personalidade jurídica:

DECISÃO: ACORDAM os Desembargadores integrantes da 15ํㅡㄹ Câmara Cível do Tribunal de Justiça do Estado do Paraná, por unanimidade de votos, em conhecer do recurso de apelação e negar-lhe provimento para manter a sentença em sua integralidade. EMENTA: APELAÇÃO CÍVEL. FRAUDE À EXECUÇÃO. CARACTERIZAÇÃO. DESCONSIDERAÇÃO DA PERSONALIDADE JURÍDICA INVERSA. POSSIBILIDADE. PREENCHIMENTO DOS REQUISITOS LEGAIS. ÔNUS SUCUMBENCIAIS MANTIDOS. Presente a confusão patrimonial entre a executada e a empresa da qual é sócia mostra-se possível a penhora de bem imóvel pertencente à esta, afastando-se o princípio da autonomia patrimonial da pessoa jurídica, para responsabilizar a sociedade por obrigação do sócio, em homenagem à desconsideração inversa da personalidade jurídica, especialmente porque também demonstrada a insolvência da devedora. RECURSO NÃO-PROVIDO (PARANÁ, 2008).

Verificada a situação de sócio que atua de forma a burlar a lei, prejudicando o pagamento de suas dívidas, sejam elas provenientes do âmbito familiar, social, ou empresarial. A relevância é que, uma vez praticada a hipótese de fraude, simulação ou abuso do direito, o sócio da sociedade empresária atua de forma negativa no aspecto empresarial, porque envolve patrimônio seu em prol da sociedade e em detrimento de terceiros.

Sejam então os débitos de natureza alimentar, empresarial ou quaisquer outros do gênero, há de ser aplicada a desconsideração inversa da personalidade jurídica, quando houver a comprovação de fraude, simulação e/ou abuso do direito por parte do sócio, transferindo seus bens à pessoa jurídica.

O devedor que transfere seus bens para a pessoa jurídica sobre a qual detém absoluto controle e continua a usufruí-los, apesar de não serem de sua propriedade, mas da pessoa jurídica controlada e, com referência aos seus credores, em princípio, não podendo responsabilizá-lo executando tais bens, nada mais certo e justo que desconsiderar inversamente a personalidade jurídica quando houver a comprovação que o sócio agiu com fraude, simulação e/ou abuso de direito em 
face desses credores. Neste caso, há o efetivo alcance dos bens patrimoniais da sociedade, quando esta for utilizada como um esconderijo de bens que eram antes de propriedade do sócio.

Conclui-se que, com base na hermenêutica, nos princípios estudados, há a relevância da Teoria às Avessas hodiernamente, embasamentos legais surgem em decorrência do Estado Contemporâneo, da Globalização, dos aspectos práticos. Jurisprudências existem e são várias, em que os Juízes de Direito acatam a ideia da desconsideração inversa da personalidade jurídica aplicada em favor de pessoas de boa-fé e em prejuízo dos enganadores, fraudadores, que são os sócios das sociedades empresárias que transferem seus bens particulares à sociedade empresária sob o aspecto de que o manto da autonomia patrimonial os beneficiará, seja a dívida oriunda de qualquer espécie (comercial, familiar).

Tal questionamento merece respeito e crédito na atual legislação brasileira, principalmente quando a ideia central decorre de embasamentos justificados no ideal de justiça e de praticidade, desde que preenchidos os pressupostos ensejadores de tal instituto e devidamente fundamentados pelo aplicador da lei.

\section{CONCLUSÃO}

O presente estudo revelou a preocupação na concretização de direitos infringidos pelos sócios de uma sociedade empresária em face de terceiros envolvidos numa relação seja comercial ou familiar.

Aspectos doutrinários e jurisprudenciais foram expostos de forma a tornar reverenciado o presente trabalho, resgatando a principiologia, que é primordial ao sistema jurídico brasileiro atual, proporcionando a sua relevância diante de situações conexas com a realidade.

Os avanços surgidos têm sido avaliados como renovadores das próprias leis; a globalização fez progredir o atual sistema que está sendo analisado com intenções baseadas em fatos reais pelos julgadores, adaptando os regramentos, os dispositivos legais à atualidade.

O ser humano com as modificações lhe apresentadas a todo instante mereceu tratamento igualitário e digno quanto à efetivação de seus direitos, até então inexistentes no atual sistema jurídico, mas que balisadores de uma progressão avançada e eficaz conforme relatos e confirmações positivas por parte do magistrado, acatando e deferindo a desconsideração da personalidade jurídica de forma inversa, ante à comprovação da fraude, simulação e/ou abuso por parte do sócio, quando este transfere seus bens particulares para a sociedade empresária com o fito de não quitar seus débitos, sejam eles de natureza comercial ou familiar.

Comprovou-se através das jurisprudências e doutrinas a relevância do direito 
empresarial nas questões comerciais e inclusive nas questões de direito de família, quando o sócio da sociedade empresária, com o escopo de não quitar o débito alimentar ou, mesmo, para não partilhar seus bens, age com má-fé transferindo seus bens particulares à sociedade empresária, sob o argumento de que o princípio da autonomia patrimonial o protegerá.

A teoria às avessas ou a desconsideração da personalidade jurídica de forma inversa vem com o argumento de que, através de embasamentos legais já existentes, o magistrado demonstrando o ideal de justiça aplica a referida lei de forma inversa, ou seja, efetiva o direito atacado, desconsiderando a personalidade jurídica da sociedade empresária a fim de quitar débitos particulares do próprio sócio, em virtude de o mesmo ter agido de forma fraudulenta, simulada e/ou abuso de direito.

Tecidos os comentários acima, necessário finalizar o presente estudo levandose em consideração a exposição de que o ser humano, diante de uma situação e mundo globalizado lhe apresentados, deve o magistrado, estando envolto de regras e opiniões das mais variadas, aplicar os dispositivos legais valendo-se de conceitos e base principiológica a fim de garantir a efetivação dos direitos transgredidos.

Notou-se a real ligação entre a principiologia, mesmo que de forma implícita, e as regras pré-existentes no ordenamento jurídico, assim como a relevância da hermenêutica num mundo globalizado merecedor de avaliações.

O legislador, assim como o aplicador e o próprio intérprete devem possuir embasamentos suficientes para que o direito atual seja devidamente concretizado, diante de casos apresentados hodiernamente, com os avanços tecnológicos e, revelados diante das situações processuais entre os jurisdicionados.

A relevância do presente trabalho se tornou efetivada diante dos argumentos apresentados, principalmente em decorrência das jurisprudências e o real sentido de justiça, utilizado em todas as decisões pelos magistrados. O imperativo de inclusão de regramento específico sobre o assunto é interessante e pertinente, levando-se em consideração os avanços sofridos pelo ordenamento jurídico nos últimos anos.

\section{REFERÊNCIAS}

AGUIAR JR, Ruy Rosado. Responsabilidade política e social dos juízes nas democracias modernas. Revista jurídica, São Paulo, v. 54, n. 350, p. 213-235, dez. de 2006.

BONAVIDES, Paulo. Curso de Direito Constitucional. São Paulo: Malheiros, 1993. 
COELHO, Fábio Ulhoa. Curso de Direito Comercial. São Paulo: Saraiva, 1999.

GOMES, Sérgio Alves. Hermenêutica Constitucional. Curitiba: Editora Juruá, 2008.

GONÇALVES, Carlos Roberto. Direito Civil Brasileiro. 7 ed. São Paulo: Editora Saraiva, 2009.

GRAU, Eros Roberto. A ordem econômica na Constituição de 1988. 7 ed. São Paulo: Malheiros, 2002.

GRAU, Eros Roberto. A ordem econômica na Constituição de 1988 (interpretação e crítica). São Paulo: Revista dos Tribunais, 1990.

GUSMÃO, Mônica. Direito Empresarial. 4 ed. Niterói/Rio de Janeiro: Editora Impetus, 2005.

HIRONAKA, Giselda M. F. Novaes. Direito de Empresas. v. 6. São Paulo: Editora Revista dos Tribunais, 2008.

JAQUES, Paulino. Da igualdade perante a lei. 2 ed. Rio de Janeiro: Forense, 1957.

MELO, Celso Antonio Bandeira de. Elementos de Direito Administrativo. São Paulo: Editora RT, 1980.

PARANÁ. Tribunal de Justiça. 15a Câmara Cível. Apelação Cível no 0504400-6. Relator: Hayton Lee Swain Filho. Julgado em 06/08/2008.

REALE, Miguel. Filosofia do Direito. 11. ed. São Paulo: Saraiva, 1986.

REQUIÃO, Rubens. Curso de Direito Comercial. 27. ed. São Paulo: Saraiva, 2008. v. 1.

RIO GRANDE DO SUL. Tribunal de Justiça. 7a Câmara Cível. Agravo de Instrumento $n^{o}$ 593074602. Relator: Paulo Heerdt. Julgado em 27/08/1993.

RIO GRANDE DO SUL. Tribunal de Justiça. 7aㅡ Câmara Cível. Apelação Cível $n^{\circ}$ 598082162. Relator: Des. Maria Berenice Dias. Julgado em 24/06/1998.

RIO GRANDE DO SUL Tribunal de Justiça. 3aㅡ Câmara Cível. Agravo de Instrumento $n^{\circ}$ 70005085048. Relator: Eduardo Kraemer. Julgado em 25/05/2004.

RIO GRANDE DO SUL. Tribunal de Justiça. 8 $8^{\underline{a}}$ Câmara Cível. Apelação Cível no 70012310058. Relator: Rui Portanova. Julgado em 27/04/2006.

ROTHENBURG, Walter Claudius. Princípios constitucionais. Porto Alegre: S. A. Fabris Editor, 1999. 
SANTA CATARINA. Tribunal de Justiça. 3o Câmara de Direito Comercial. Agravo de instrumento n. 2005.031945-4, de Canoinhas. Agravante: Jairo César de Carvalho. Agravado: Bierville Distribuidora de Bebidas Ltda. Relator: Des. Marco Aurélio Gastaldi Buzzi. DJSC Eletrônico, n. 56, p. 30, 19 set. 2006. Disponível em: $<$ http://www.tj.sc.gov.br/institucional/diario/a2006/20060005600.PDF>.Acesso em: 30 set. 2010.

SÃO PAULO. Tribunal de Justiça. $2^{\underline{a}}$ Câmara Cível. Apelação Cível $n^{\circ} 142812$. Relator: Bueno Magano. Julgado em 26/04/1989.

SÃO PAULO. Tribunal de Justiça. 7ª Câmara Cível. Apelação Cível no 206787-2. Relator: Pinheiro Franco. Julgado em 17/06/1993.

SÃO PAULO. Tribunal de Justiça. $3^{\underline{a}}$ Câmara de Direito Privado. Apelação Cível no 86.249-4. Relator: Octávio Helene. Julgado em 05/11/1998.

Artigo recebido em 09/09/10 e aprovado para publicação em 20/10/10 